\title{
Anterior Dental Crossbite Correction: An Esthetic Makeover
}

\author{
Chaithra P Remadevi ${ }^{1}$, Saravanakumar M Subramani ${ }^{2}$, Anjana Gopalakrishnan ${ }^{3}$, Muralikrishnan Balachandran ${ }^{4}$
}

\begin{abstract}
Anterior dental crossbite is commonly seen in children who have malocclusion. Early diagnosis and correction of anterior crossbite may prevent the adverse effects upon the growth and development of a child. Different techniques have been used to correct anterior crossbite in mixed dentition. The present case reports describe the successful management of anterior dental crossbite with removable and fixed appliances. These appliances can be used as an alternative technique for the management of anterior dental crossbite.
\end{abstract}

Keywords: $2 \times 4$ appliance, Anterior crossbite, Expansion appliance, Malocclusion.

Journal of South Asian Association of Pediatric Dentistry (2019): 10.5005/jp-journals-10077-3018

\section{INTRODUCTION}

Anterior crossbite is a malocclusion in which one or more of the maxillary anterior teeth occlude palatally to the mandibular incisors. If it occurs due to the palatal malposition of a maxillary tooth with associated labioversion of contacting mandibular teeth, then it is called dental crossbite. ${ }^{1}$

Trauma to the primary incisor with a displacement of the permanent tooth bud, supernumerary anterior teeth, odontomas, crowded incisor, and delayed exfoliation of the primary incisors are the common etiological factors for this condition. Several treatments have been applied for the correction of anterior crossbite. The appliance needed for the correction of crossbite should be inexpensive, comfortable, and easily tolerated. Early correction of this malocclusion will prevent further complications. ${ }^{2-5}$

Following are the case reports of patients with anterior dental crossbite and their management.

\section{Case Description}

\section{Case 1}

A 12-year-old female patient reported at the Department of Pedodontics and Preventive Dentistry with a chief complaint of the backwardly placed upper front tooth since the time of eruption. On examination, 21 was found to be in crossbite (Fig. 1). She had a history of over-retained left primary maxillary central incisor. She presented with the class I molar relation with mandibular incisor crowding and rotated 32 .

Orthopantomogram (OPG) was taken to rule out the presence of odontome in relation to the tooth in crossbite. The amount of root formation was also assessed from the OPG. The model analysis revealed that both arches had $\leq 2 \mathrm{~mm}$ of the arch length-tooth material discrepancy. So non-extraction correction with fixed appliance was decided.

The treatment was divided into three phases.

\section{First Phase}

The main objective of this phase was to correct the crossbite. In this phase, the treatment plan composed of $2 \times 4$ appliance therapy in both the maxilla and the mandible. Maxillary and mandibular incisors were bonded with preadjusted edgewise brackets and the first molars were banded. The occlusal clearance for 21 was done with composite build-up on the mandibular first molars. \begin{tabular}{l}
\hline${ }^{1-4}$ Department of Pediatric Dentistry, Royal Dental College, Palakkad, \\
Kerala, India \\
Corresponding Author: Saravanakumar M Subramani, Department \\
of Pediatric Dentistry, Royal Dental College, Palakkad, Kerala, India, \\
Phone: +919444522345, e-mail: drsaravanapedo@gmail.com \\
How to cite this article: Remadevi CP, Subramani SM, et al. Anterior \\
Dental Crossbite Correction: An Esthetic Makeover. J South Asian \\
Assoc Pediatr Dent 2019;2(1):29-31. \\
Source of support: Nil \\
Conflict of interest: None \\
\hline \hline
\end{tabular}

In this case, the brackets on 21 and 32 were rotated by $180^{\circ}$ (Fig. 2). This helps counteract the palatal torque of the roots of 21 and $32 .{ }^{6}$ The brackets were engaged with $0.016^{\prime \prime}$ ovoid NiTi initially. Review after 8 weeks revealed a positive overjet in relation to 21 . Composite build-up on mandibular molars was removed.

\section{Second Phase}

In this phase, space creation for the derotation of mandibular incisor was planned. For that, brackets were bonded from the mandibular left second premolar to right second premolar. About 0.017 " $\times$ 0.023 " rectangular NiTi wire then replaced the round $\mathrm{NiTi}$.

Five months later, the lower arch wire changed to $0.017^{\prime \prime} \times$ $0.023^{\prime \prime}$ rectangular stainless steel (SS) and then an open coil was compressed between the mandibular left central incisor and the left canine to regain the space needed for the derotation of the mandibular left lateral incisor. An adequate space was created for the rotation of 32 after 2 weeks.

\section{Third Phase}

In the third phase, lingual buttons were bonded on the lingual surface of the mandibular left first premolar and the mandibular left lateral incisor. Then, two elastomeric chains were used to derotate the lateral incisor (32). The first elastomeric chain was extended between the labial bracket of 32 and the lingual button of 34 . The second elastomeric chain was extended between the lingual button on 32 and brackets of 31 and 41 (Fig. 3).

The rotation correction of 32 was achieved after 3 months (Fig. 4). After debonding the appliance, a fixed lingual retainer was given to retain the corrected position of 32 . 


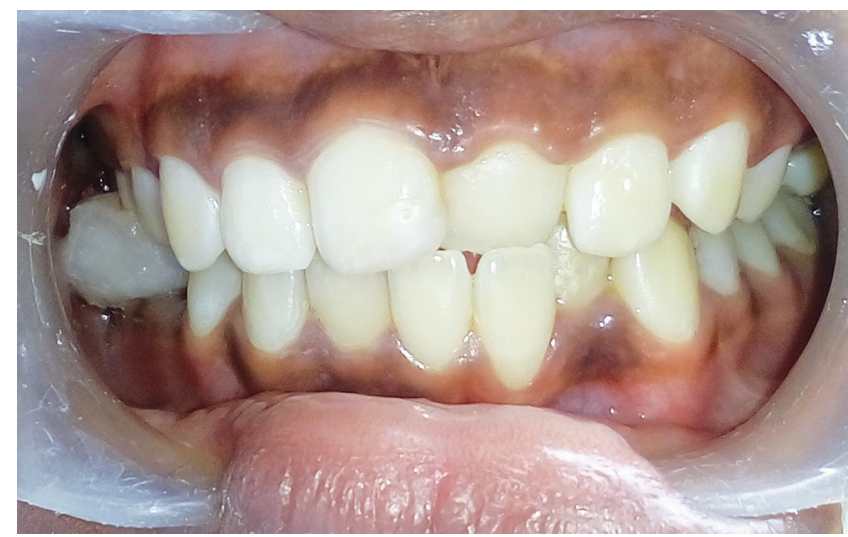

Fig. 1: Preoperative view

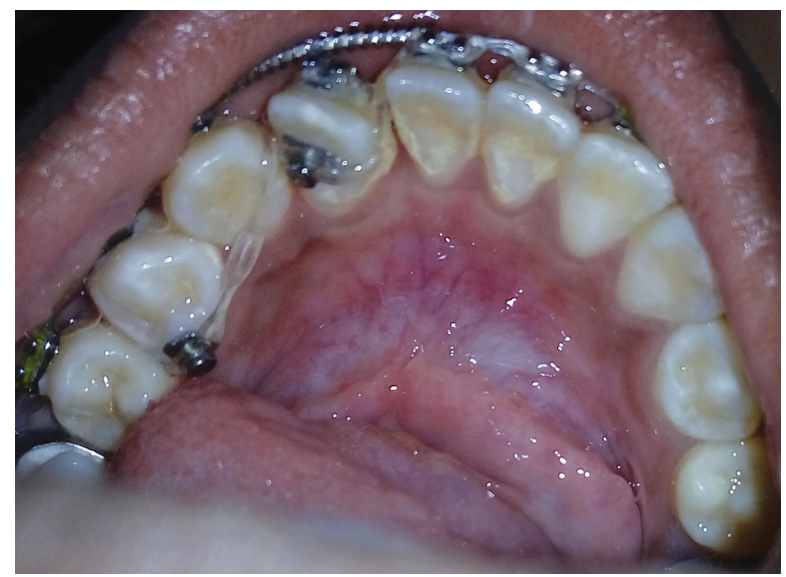

Fig. 3: Fixed lingual buttons

\section{Case 2}

A 9-year-old female patient came to our department with a chief complaint of an unesthetic smile. Extraoral examination revealed straight profile and competent lips. Intraoral examination showed that maxillary central incisors and left lateral incisor were in crossbite (Fig. 5).

The lateral cephalometric analysis showed no evidence of the skeletal problem in maxillary and mandibular arches. Since the maxillary incisors were retroclined relative to the basal bone, the malocclusion was diagnosed as an anterior dental crossbite. The treatment objectives for the patient were to correct an anterior crossbite, to establish normal overbite and overjet, and also to improve esthetics. Treatment decisions should depend on the number of teeth involved, age of the child, eruption status of the involved tooth, oral hygiene of the patient, etc. Removable appliances are safe and esthetically acceptable and can be successfully given to cooperative patients.

In this case, three teeth in the maxillary anterior segment were involved. So a segmental expansion was planned with a removable appliance with a jackscrew and bilateral posterior bite plane (Fig. 6). The patient was instructed to activate the screw once in every alternate day by a quarter turn of the screw in the anticlockwise direction. After 4 weeks, the crossbite was corrected with adequate overjet and overbite (Fig. 7). The appliance was removed after 6 weeks.

\section{Discussion}

Anterior crossbite is the term used to define the lingual positioning of the maxillary anterior teeth in relation to the mandibular anterior

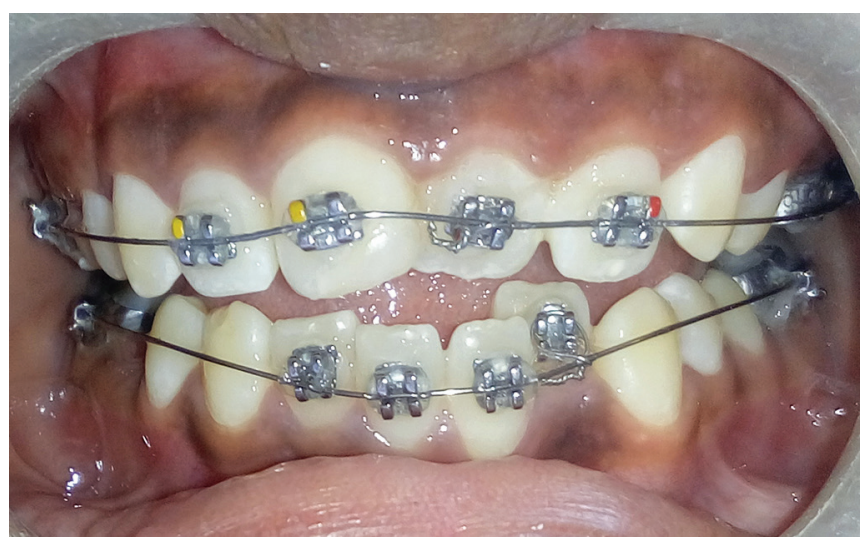

Fig. 2: $2 \times 4$ appliance in place

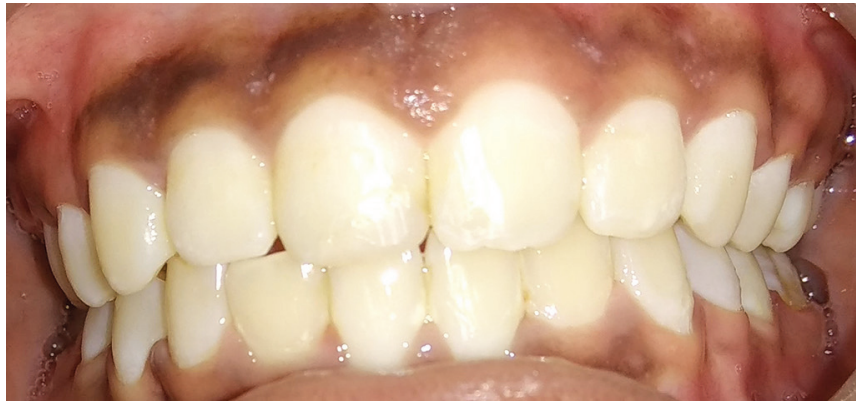

Fig. 4: Postoperative view

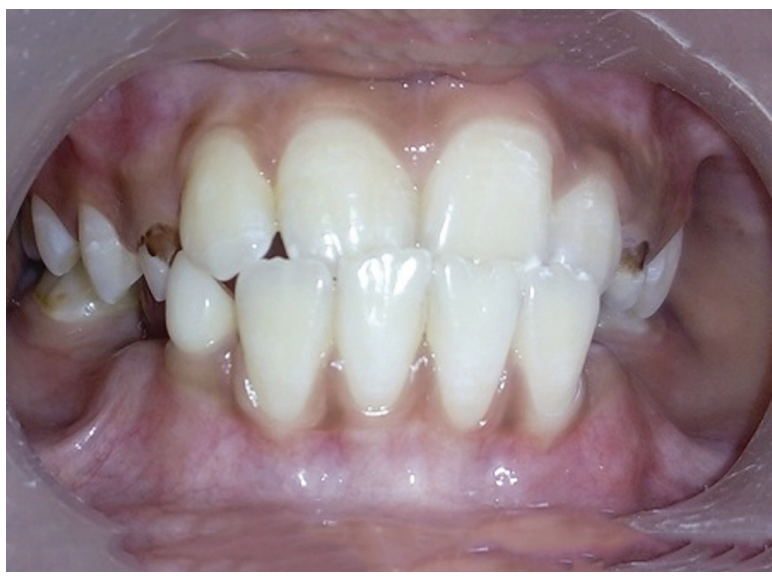

Fig. 5: Preoperative view

teeth. ${ }^{7}$ The prevalence of anterior crossbite is found to be $4-5 \%$ and usually becomes evident during the early mixed dentition period. ${ }^{2}$ Anterior crossbite should be intercepted and treated as early as possible. If not treated early, it has the potential of growing into skeletal malocclusion. Crossbite of dental origin can be treated using both removable and fixed appliance.

Anna Paulina and Lars Bondemark had done a randomized controlled trial in 2015 to compare the effectiveness of fixed and removable appliance in correcting anterior crossbite and concluded that this can be successfully corrected by either removable or fixed appliance therapy. ${ }^{8}$

The patient in the first case report had anterior crossbite and crowding. Tipping movements are much less effective in producing derotation; hence, fixed appliance therapy was planned. Removable appliances produce tipping movement rather than bodily movement. ${ }^{9}$ 


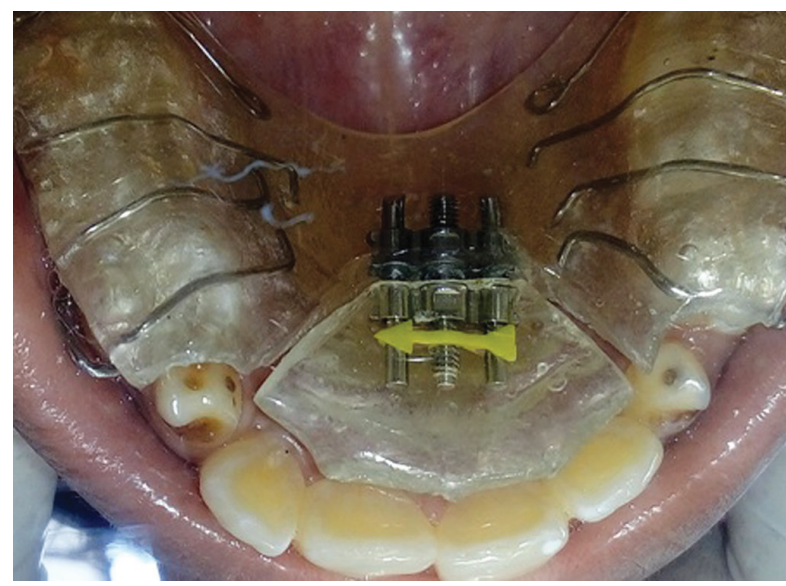

Fig. 6: Intraoral view of the appliance

Moreover, in the Arch perimeter analysis, the arch length-tooth material discrepancy was found to be $1.5 \mathrm{~mm}$ in the upper arch and $2 \mathrm{~mm}$ in the lower arch, so a non-extraction therapy was planned.

The fixed appliance consists of $2 \times 4$ or $2 \times 6$ therapy which offers a more effective and efficient tooth positioning and maintains a good arch form. More chair side time is required only at the time of appliance fixation. Without involving the entire dentition, a single or few teeth alignment is possible by this technique. It also prevents further complications of malocclusion if left untreated by early correction. The disadvantage of this appliance is the limited anchorage provided by just maxillary and mandibular first molars. ${ }^{6}$

Preadjusted edgewise brackets are the ones that are designed to guide the tooth without any wire bending. NiTi arch wires are used mainly because of their unique properties of superelasticity and shape memory which are chiefly used to align severely malpositioned teeth. ${ }^{10}$ Since open coil spring offers with a quick and comfortable approach compared to disking the teeth, it was used to regain space in case.$^{11}$

Behrents stated that the mandibular arch should be retained after orthodontic correction until the eruption of the third molars. ${ }^{12}$ In this case, the coaxial wire was used as a fixed lingual retainer. It has mechanical advantages of multistranded cables and the properties of super elastic archwires. In the case of anterior crossbite correction when the incisor overbite and posterior intercuspation are adequate for maintaining the correction, no retention is necessary. So no retention appliance was given in the upper arch. ${ }^{13}$

In the second case, the expansion screw was used for the crossbite correction. Treatment with removable appliances will help in the maintenance of good oral hygiene. Etching, bonding, and debonding procedures can be avoided. Moreover, they reduce the chair side time. However, the success of therapy depends on good patient cooperation. ${ }^{9}$ Since removable segmental expansion appliance is an effective method for the labial tipping of maxillary incisors, the correction was done with removable jack screw appliance.

The activation was done one quarter turn every alternate day. A single quarter turn produces $0.25 \mathrm{~mm}$ of tooth movement. This compresses the teeth in the socket by $0.12 \mathrm{~mm}$ per side, which is within the width of the periodontal ligament. ${ }^{14}$ The duration of treatment with removable appliances is reported to range from 6 to 12 weeks. ${ }^{15}$ In this case, the correction was achieved by 4 weeks.

\section{CONCLUSION}

The above-mentioned cases describe the acceptable alternative methods for the correction of anterior dental crossbite. Crossbite

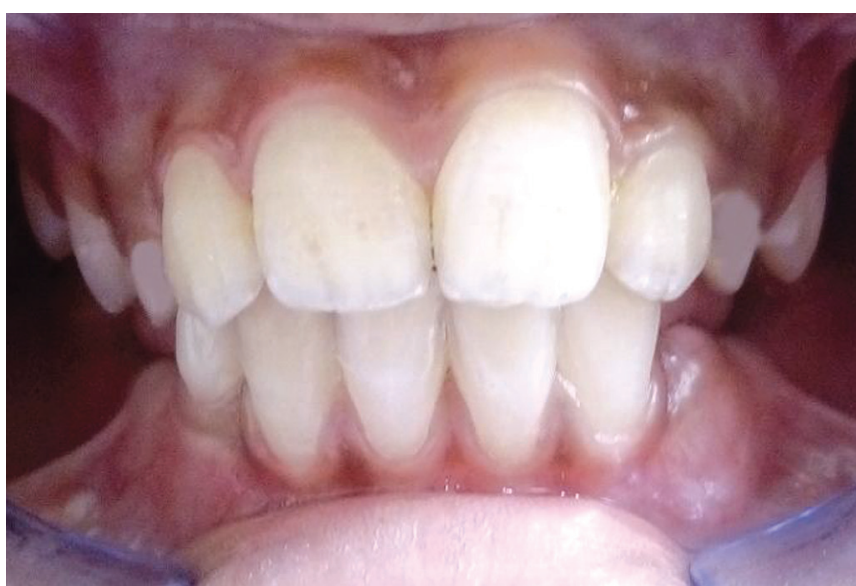

Fig. 7: Posttreatment view

if left untreated can lead to oral health problems like traumatic occlusion, resulting in attrition of teeth, mobility, and apical migration of labial gingiva. Therefore, early diagnosis and correction of anterior crossbite may prevent the adverse effects upon the growth and development of the child.

\section{References}

1. Agarwal A, Mathur R. Segmental orthodontics for the correction of cross bites. Int J Clin Pediatr Dent 2011 Jan-Apr;4(1):43-47. DOI: 10.5005/jp-journals-10005-1080.

2. Major PW, Glover K. Treatment of anterior cross bites in the early mixed dentition. J Can Dent Assoc 1992 Jul;58(7):574-578.

3. Hannuksela A, Vaananen A. Predisposing factors for malocclusion in 7 years children with special reference to atopic diseases. Am J Orthod Dentofacial Orthop 1987 Oct;92(4):299-303. DOI: 10.1016/08895406(87)90330-1.

4. Hannuksela A, Laurin A, et al. Treatment of crossbite in the early mixed dentitions. Proc Finn Dent Soc 1988;84(3):175-182.

5. Kharbanda O, Sidhu S, et al. A study of the etiological factors associated with the development of malocclusion. J Clin Pediatr Dent 1994;18(2):95-97.

6. Fatima J, Jain $\mathrm{P}$, et al. A witty hand of orthodontic treatment-fixed partial appliance. Int J Appl Dent Sci 2015;1(3):86-89.

7. Tsai HH. Components of anterior crossbite in the primary dentition. ASDC J Dent Child 2001 Jan-Feb;68(1):27-32.

8. Wiedel AP, Bondemark L. Fixed vs removable orthodontic appliances to correctanterior crossbite in the mixed dentition - a randomized controlled trial. Eur J Orthod 2015 Apr;37(2):123-127. DOI: 10.1093/ejo/cju005.

9. Ulusoy AT, Bodrumlu EH. Management of anterior dental crossbite with removable appliances. Contemp Clin Dent 2013 AprJun;4(2):223-226. DOI: 10.4103/0976-237X.114855.

10. Kusy RP. A review of contemporary archwires: their properties and characteristics. Angle Orthod 1997 June;67(3):197-207. DOI: 10.1043/0003-3219(1997)067.

11. Gawthaman M, Disha P, et al. A fixed partial appliance approach towards treatment of anterior single tooth crossbite: report of two cases. Indian J Dent Sci 2017 Mar;9(2):119-121.

12. Zachrisson BU. Important Aspects of Long-Term Stability. J Clin Orthod 1997 Sep;31(9):562-583.

13. Kaplan $\mathrm{H}$. The logic of modern retention procedures. Am J Orthod Dentofacial Orthop 1988 Apr;93(4):325-340. DOI: 10.1016/08895406(88)90163-1.

14. Manoharan M, Disha P, et al. Correction of anterior crossbite with different approaches: a series of three cases. Int J Oral Health Med Res 2016;3(3):41-43.

15. Kennedy DB, Osepchook M. Unilateral posterior crossbite with mandibular shift: a review. J Can Dent Assoc 2005 Sep;71(8):569-573. 